\title{
Cognition of Mainstream Culture and Subculture in English-speaking Countries
}

\author{
Gaimei Zhao \\ Xi'an Peihua University, Xi'an 710125, China \\ 1142626982@qq.com
}

\begin{abstract}
This paper explains how to cognize the mainstream culture and subculture in English-speaking countries. There are many different kinds of cultures in the world, and some of them are mixed while others are not. Most of cultures have been kept for thousands of years. Mainstream culture is widespread, the culture of most people and the normal way of action. Mainstream cultures are typically disseminated by mass media. A subculture differs in one or more ways from the mainstream culture. Subcultures are norms and values which are distinct from the majority and a group within a wider society. The paper states that the English language is widely dispersed around the world in which the youth can identify themselves with a subculture on different levels. The youth think that they can gain social status and respect within the subculture by identifying and being good at a subculture. In the paper the author shows that the study of subcultures is often made up of the study of symbols which are attached to clothing, music and other visible affectations by members of subcultures.
\end{abstract}

Keywords: mainstream culture; subculture; cognition

\section{Introduction}

Culture is important because it influences an individual's life in a variety of ways, including values, views, desires, fears, views and worries. Culture incorporates nearly all the experience shared by human beings, who are naturally drawn to participate in culture because they are social creatures. Group culture states the norms for the group, which modify their behavior in exchange for protection in numbers and acceptance into the group. Although the behavioral rules may be vague laid out by culture, these rules are much more enforced now than ever by the mass dissemination of culture. [1]

There are many different kinds of cultures around the world, some of which are mixed while others are not. Most cultures have been kept for thousands of years, helping to connect human beings through material and goods. Belonging to a culture can provide people with an easy way to communicate with others who share the same mindset and values. No matter where you are, in small villages or in larger cities, cultures offer you a chance to connect and share each other's history and ideas. When cultural expectations become more entrenched, they are more influential at affecting both individual and group behavior.

\section{Explanation of some concepts in the paper}

\subsection{Concept of mainstream culture}

Mainstream culture is widespread current thought, including all popular culture and media culture, typically disseminated by mass media. Mainstream culture is held within a large amount of people residing in a society, the culture that seems the most common to those who live in a specific area. Mainstream is the principle, and culture is the caliber in an individual or a big group. So when you put them together, mainstream culture is to be distinguished from subcultures. [2]

\subsection{Concept of subculture}

A subculture is a group of people with different ideologies of the larger culture they are a member of. Many subcultures also dislike the mainstream culture. Several subcultures flourish because of the almost genetic need for people to belong, especially the youth. Because of this, many companies have taken notice of them and begun to exploit subculture's music or fashion tastes. This may result in a complete change of the original intentions of the group. [3] A subculture is a cultural 
group within a culture which is different in one or more ways from the culture including differences in interest, behaviors or beliefs, like religion, ethnicity, and social or economic status. When small groups are inclined to be culturally uniform, large industrial communities are culturally diverse and include many different subcultures. Subcultures are values and norms that are distinct from the majority and are held by a group within a wider society.

\subsection{Concept of Social cognitive theory}

Social cognitive theory is used in psychology, education, and communication, holding that parts of an individual's knowledge acquisition can be directly connected to observing others within the context of social interactions, experiences, and outside media influences. The theory states that when people observe a model performing a behavior and the consequences of that behavior, they remember the sequence of events and use this information to guide subsequent behaviors. In other words, the survival of humanity relies upon the replication of the actions of others. Depending on the results of the behavior, the observer may choose to replicate behavior. [4]

Social cognitive theory is a learning theory which is based on the idea that people learn something by observing others. These behaviors learned can be basic to one's personality. The individual is just as important as the environment one grows up in and the both contribute to the people's behavior. People learn by observing others, with the environment, behavior, and cognition all as the elementary factors in influencing people's development. Each behavior can change a person's way of thinking.

\section{Cultures in English-speaking countries}

\subsection{Mainstream culture in English-speaking countries}

There are six countries with a majority of native English speakers, the United States, the United Kingdom, Canada, Australia, Ireland, and New Zealand included. Children in these countries learn English from their parents, and local people with other languages or new immigrants have to learn English to communicate in their neighborhoods and workplaces.

Mainstream American culture is said to be a western culture, largely passed down from societal traditions and values of European immigrants and other sources, such as traditions and values of slaves brought from Africa. Later immigration from East Asia and Latin America have influenced mainstream culture. These features, including honesty, equality and self-reliance, remain a part of the American cultural dialogue over the years. It is these values that represent the mainstream culture in America.

The United Kingdom is prominent in science and technology. Sport is also an important part of British culture; numerous sports originated in the country, including football. The UK has been described as a cultural superpower, and London has been described as a world cultural capital.

Canada's culture derived from its wide range of nationalities and policies that promote a just society. Canadian government policies, like outlawing punishment; health care; higher and more progressive taxation; efforts to eliminate poverty; gun control; an emphasis on cultural diversity, are social indicators of its political values and cultural values.

In Australia, the diverse food, cultural practices and lifestyles of immigrants have been absorbed into mainstream culture over time. Egalitarianism, informality and an irreverent sense of humor have been common themes of cultural commentary.

Irish culture has a global reach and festivals are celebrated all over the world. Due to large-scale emigration from Ireland, Irish culture has to some degree been inherited and modified by the Irish diaspora, which in turn has influenced the home country.

The culture of New Zealand is largely inherited from British, Oceanian customs and European customs, together with Maori and Polynesian tradition. New Zealand has a cosmopolitan, multicultural culture that reflects it's an educated, developed Western society. [5]

\subsection{Subculture in English speaking countries}

There is the subculture of Goths in the United States that younger people dress in black and tend to idolize such poets asShelly and Keats and seem to admire werewolves and vampires. There is the 
subculture of skateboarders evolving into the subculture of extreme sports enthusiasts. There is the gay culture which constitutes a subculture.

In UK, young people demanded freedom to behave as they wished partly based on prosperity when young people had disposable incomes to play with as the result of earnings increasing. Mods or Moderns were fashion-conscious sharp dressers of the 1960s, partly from the jazz modernists in 1950s. At the beginning of 1970s, Skinheads become connected with racism. In the mid-1970s Punks emerged as another aggressive group, promoting themselves as the blank generation.

In Canada hippies were characterized by long hair, beards and unconventional clothing, by their celebration of drugs and rock'n roll. Although they were widely ridiculed, they upheld communal life, egalitarianism, pacifism, and self-help, and were hostile to private property, technology and bureaucracies. As a mass phenomenon the hippies were short-lived.

In Australia, subcultures might include hippies, Goths, fans of hip hop or heavy metal and even bikers. A deviant subculture has values and norms that differ substantially from the majority of people in a society.

American television programs, clothing, music, sports and film stars, took New Zealand by storm during the late 1970s and 1980s. Youth street gangs became common in the cities who attempted to emulate the romanticized version of gang life that the movie Colors depicts[6].

\section{Cognition of mainstream culture and subculture in English speaking countries}

Social cognitive theory is centered on the process of knowledge acquisition. The models can be an interpersonal imitation. Effective modeling teaches general rules and strategies for dealing with different situations. Modeling can be live demonstrations, and verbal and written behavior can be indirect forms of modeling. Modeling allows students to learn behavior by repetition. On the other hand, modeling is probably to inhibit certain behaviors. When people repeat the behavior, they must understand what the potential outcome it is.

Identification allows people to feel a similarity with the model, and can thus lead to a higher chance of the people following through with the model. People are more likely to follow behaviors modeled by someone with whom they can identify with.

\section{Conclusions}

Young people can identify with a subculture on a number of different levels. By identifying and being good at a subculture, a young person can gain status and respect within the subculture. Mainstream or ethnic culture remains their main source of identity. Young people may think that the subculture can offer them a way of asserting their independence and show that they are different from their parents. They agree that there are things in the subculture that they are good at or know more about. They admit that the subculture is part of their identity, which provides them with more opportunities to have supportive relationships with others who understand them well. [7]

Youth in a subculture may experience negative labeling and discrimination from others in the community. While some youth subcultures, such as gangs, do take part in some behaviors that are dangerous, unlawful, which may cause some problems for the young persons and the society. Social modeling provides an identifiable model which states the processes performing a behavior. Verbal persuasion is providing encouragement for a person to complete a task. For example, students become more active, pay attention, highly motivated and better learners when they find that they have grasped a particular task. It is the duty of the teacher who should ensure that the students have the knowledge and strategies they need to complete the tasks. Self-efficacy has produced some of the most consistent results revealing an increase in participation in exercise. [8]

The study of subcultures often includes the study of symbolism attached to clothing, music, and also of the ways in which these same symbols are interpreted by members of the mainstream culture. Subcultures might include hippies, Goths, fans of hip hop or heavy metal and even bikers. British youth subcultures had been described as a moral problem that ought to be dealt with over long 
period. A deviant subculture has values and norms that differ substantially from the majority of people in a society.

Media played an important role in the social changes and the youth helped spread the consciousness and led to some people even thinking of the youth as a new class. Some scholars also believed that youth culture was partially created by the media, as it was a "means of imitation and manipulation on a national scale". Therefore they gave young people the choice to imitate new cultural habits in the media. While a subculture feels it is necessary to differentiate itself from the parent culture, in many cases they still preserve its traditions and identifications. A subculture can also be placed in relation to the mainstream culture. Even though a subculture will have common ideological grounds and experience with the mainstream culture, it will be likely to accept its hegemony, concern of the group. In spite of occasional expressions of resistance from both sides, they still mostly tend to coexist rather than be directly opposed. [9]

Based on these relations, some features of mainstream culture and a subculture can be listed. Actually subcultures bond around their ideas, concerns or activities. The creation of a subculture is generally seen as a sign of revolt against the natural order in the society. A certain group refuse to obey the natural order. At first an action against the order is taken in the process, and someone follows the action. Thus in the mainstream culture, an indivisible part of a subculture comes into being. [10]

\section{References}

[1] Gareis, E.. Intercultural friendship: Effects of home and host region. Journal of International and Intercultural Communication (2012).

[2] Seiler, Robert M. "Human Communication in the British Cultural Studies Tradition." http://people.ucalgary.ca/ rseiler/british.htm

[3] Bennett, Andy \&Keith Kahn-Harris , eds . After Subculture : Critical Studies in Contemporary Youth Culture. Houndmills , Basingstoke , Hampshire , NewYork : Palgrave Macmillan , 2004 .

[4] Baldwin, J. R.. Cross-cultural adaptation. (2011) http://my.ilstu.edu/ jrbaldw/372/Adaptation.htm

[5] https://www.wikipedia.org/

[6] Gallagher, H. C.. Willingness to communicate and cross-cultural adaptation: L2 communication and acculturative stress as transaction. Applied Linguistics. (2012)

[7] Hendrickson, B., Rosen, D., \& Aune, R. K. An analysis of friendship networks, social connectedness, homesickness, and satisfaction levels of internationalstudents. International Journal of Intercultural Relations (2011).

[8] Wenxin Zhang, Adolescent Development Psychology, Shandong People's Publishing House, (2003)

[9] Junru Zhao, Perspective-taking and Childern's Social Development, Journal of Zhangjiakou Teachers College, 2000, 3

[10] Jianqing Sun, Research on Educational Problem of Modern Chinese College Students' Core Values, Shandong University, 2014 